\title{
Bone marrow-derived mesenchymal stem cells (MSCs) stimulate neurite outgrowth from differentiating adult hippocampal progenitor cells
}

Eun-Ah Ye ${ }^{1,2,3}$, Sagar S. Chawla ${ }^{4}$, Michael Z. Khan ${ }^{4}$ and Donald S. Sakaguchi ${ }^{1,2^{*}}$

*Correspondence: dssakagu@iastate.edu

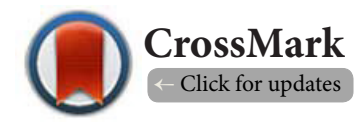

${ }^{1}$ Neuroscience Program, lowa State University, Ames, lowa, USA.

${ }^{2}$ Department of Genetics, Development and Cell Biology, lowa State University, Ames, lowa, USA.

${ }^{3}$ Department of Anatomy and Cell Biology, Wayne State University, 9314 Scott Hall, 48201, Detroit, MI, USA.

${ }^{4}$ Biology Program, lowa State University, Ames, lowa, USA.

\begin{abstract}
Background: Bone marrow-derived mesenchymal stem cells (MSCs) have emerged as beneficial cellular vehicles for nervous system rescue and repair. A better understanding how MSCs are involved in mediating neural repair will facilitate development of novel therapeutic strategies.

Methods: In the present study bone marrow-derived MSCs were isolated and characterized from Brown Norway rats. The capacity of the MSCs to influence the differentiation of adult hippocampal progenitor cells (AHPCs) was investigated using contact and non-contact co-culture configurations.

Results: These MSCs showed a stable and consistent growth rate, retained short population doubling time (PDT) and showed high capacity of cell proliferation. Co-culturing of AHPCs with MSCs did not appear to significantly affect the proliferation of the AHPCs or impact the proportion of neuronal or glial differentiation of the AHPCs. However, both contact co-culture (CCC) and non-contact co-culture (NCCC) significantly promoted neurite outgrowth from neuronal AHPCs.

Conclusions: The ability of MSCs to promote the morphological differentiation of AHPCs may serve as an added benefit when developing cell-based strategies for nervous system rescue and repair.

Keywords: Bone marrow-mesenchymal stem cells, MSC, neural stem cells, neural progenitor cells, neurite outgrowth, regeneration, adult stem cells, neurorepair
\end{abstract}

\section{Introduction}

Mesenchymal stem cells (MSCs) have become an important cell source for treatment of neurodegenerative conditions as well as in nerve repair strategies. Gaining a better understanding of how MSCs mediate neural repair will benefit the development of novel therapeutic strategies [1-4]. Multipotent bone marrow-derived MSCs can be readily isolated due to their characteristic adherence to tissue culture polystyrene surfaces and have the ability to self-renew and can differentiate into various mesodermal lineages such as bone, cartilage, and fat cells [5]. Importantly, bone marrow-MSCs are a potential candidate for autologous transplantation, thus avoiding an immune response in the host. Mesenchymal stem cells also display paracrine activity, secreting bioactive neuroprotective molecules (reviewed in [6]). In addition to bone marrow, MSCs have been isolated from a variety of tissues such as fetal pancreas [7], liver [8], umbilical cord blood [9], scalp tissue [10], fetal thymus [11], adipose tissue [12], vermiform appendix [13], placenta [14], and endometrium [15]. However, MSC isolation from bone marrow is a relatively common procedure and is clinically relevant $[16,17]$.

Bone marrow-MSCs isolated from different rat strains- Fisher, Lewis, Sprague-Dawley and Wistar- have been well characterized [18]. However, MSCs from the bone marrow of Brown Norway rats (Rattus norvegicus), have not been studied systematically. Brown Norway rats are a relatively common animal model 
Ye et al. Stem Cell Biology and Research 2016,

used for biomedical research [19-24]. They are well-defined genetically, physiologically, and behaviorally [19,25-29]. There are, to our knowledge, no established resources and studies performed on bone marrow-MSCs from Brown Norway rats. Thus, the isolation and systematic examination of MSCs from this strain is required to broaden the availability of cell lines for autologous or syngeneic transplants for further development of experimental strategies for neurorepair.

This study was designed to characterize bone marrow-MSCs isolated from Brown Norway rats and to investigate their potential influence on differentiation of neural stem cells. Three criteria were used to define the MSCs: 1) adherence to tissue culture polystyrene (TCPS), 2) expression of specific surface antigens, and 3) multipotent differentiation potential [30]. The ability of these MSCs to stimulate differentiation and neurite outgrowth was investigated by co-culturing with adult rat hippocampal progenitor cells (AHPCs). These results demonstrated that MSCs isolated from the bone marrow of Brown Norway rats were multipotent and showed consistent cell growth and proliferation through long periods of subculture. In addition, co-cultures of MSCs with the AHPCs demonstrated their capacity to promote neurite outgrowth from neurons differentiating from AHPCs. These results provide additional support for the use of MSCs as a potent resource for the development of cell-based strategies for nervous system rescue and repair.

\section{Materials and methods}

\section{Animals}

All procedures involving animals were conducted in accordance with the guidelines published in the NIH Guide for the Care and Use of Laboratory Animals and all procedures adhered to the principles presented in the "Guidelines for the Use of Animals in Neuroscience Research" by the Society for Neuroscience. All animal procedures had the approval of the lowa State University Institutional Animal Care and Use Committee, and were performed in accordance with committee guidelines. Six-week old Brown Norway rats (one male and one female) were obtained from Charles River Labs and used for the isolation of bone marrow. The animals were kept in a constant environment (temperature: $22^{\circ} \mathrm{C}$; humidity: $20 \%$; 14/10-hour light-dark cycle) with food and water provided ad libitum until bone marrow isolations. Upon arrival, rats were allowed to adapt to their new environment for seven days before harvesting of bone marrow.

\section{Isolation and culturing of mesenchymal stem cells}

The rats were euthanized with isoflurane and then the femora and tibiae were dissected. These bones were placed in ice-cold maintenance media [MM; alpha minimum essential medium (aMEM; Gibco BRL, Gaithersburg, MD) supplemented with $20 \%$ fetal bovine serum (Atlanta Biologicals, Lawrenceville, GA), 4 mM L-glutamine (Gibco BRL, Gaithersburg, MD), and $1 \%$ antibiotic-antimycotic (Invitrogen, Carlsbad, CA)]. The bone marrow was flushed from the bones using a syringe and 23-gauge needle filled with $3 \mathrm{ml} \mathrm{MM}$ onto a $70 \mu \mathrm{m}$ filter pre-wetted with MM and transferred into a T75 flask with $20 \mathrm{ml} \mathrm{MM}$. The cell suspension was maintained in a culture incubator $\left(37^{\circ} \mathrm{C}, 5 \% \mathrm{CO}_{2} / 95 \%\right.$ humidified air atmosphere). 48 hours after harvest, spindle-shaped cells adhered to the flask and media was exchanged with fresh MM after washing with phosphate-buffered saline (PBS; Gibco BRL, Gaithersburg, $M D$ ). MSCs isolated from male and female rats were cultured separately as different cell lines. MSCs were fed with MM twice a week. When the MSCs were about $80 \%$ confluent, subculturing was performed.

\section{Population doubling time}

To evaluate the growth of MSCs, their population doubling time (PDT) was calculated using the formula PDT $=2 x+x N i / \mathrm{No}$ (t: the time required to reach $80 \%$ confluency, hr; Ni: the initial number of cells; No: the final number of cells) [31]. MSCs at passages 1, 4, 9, and 15 were investigated. The experiment was repeated three times $(\mathrm{N}=3)$.

\section{5-bromo-2-deoxyuridine (BrdU) assay}

The proliferation of MSCs was evaluated by BrdU incorporation during several passages at time points corresponding to that of the PDT analysis, (i.e., passages 1, 4, 9, and 15) BrdU is commonly used to detect cell proliferation and is incorporated into the cells in S-phase. MSCs were plated onto $12 \mathrm{~mm}$ cleaned glass coverslips at approximately $30 \%$ confluency with maintenance media (MM), and the following day BrdU solution was added ( $5 \mu \mathrm{M}$ BrdU in MM). After 24 hours, MSCs were fixed in $4 \%$ paraformaldehyde in $0.1 \mathrm{M} \mathrm{PO}_{4}$ buffer, $\mathrm{pH}$ 7.4. Fixed cells were then rinsed in PBS $(137 \mathrm{mM} \mathrm{NaCl}, 2.68 \mathrm{mM}$ $\mathrm{KCl}, 8.1 \mathrm{mM} \mathrm{Na}_{2} \mathrm{HPO}_{4^{\prime}} 1.47 \mathrm{mM} \mathrm{KH}_{2} \mathrm{PO}_{4^{\prime}} \mathrm{pH}$ 7.4) and incubated in $2 \mathrm{~N} \mathrm{HCl}$ for $15 \mathrm{~min}$ followed by $0.1 \mathrm{M}$ sodium borate solution (pH 8.5) for 5 min. After washing with PBS, MSCs were incubated in blocking solution [5\% normal donkey serum, $1 \%$ bovine serum albumin (BSA; Sigma), and 0.1\% Triton X-100 (Fisher Scientific) in PBS] for 90 minutes. To identify cells that incorporated BrdU, MSCs were incubated in anti-BrdU primary antibody (see Table 1) overnight at $4^{\circ} \mathrm{C}$ in a humid chamber, washed in PBS, and incubated in Cy3-conjugated secondary antibody for 1.5 hours in the dark. The cells were then rinsed and nuclei stained with 4', 6-diamidino-2-phenylindole, dilactate (DAPI, 1:2,000). Preparations were mounted on glass slides with Vectashield mounting media (Vector laboratories, Burlingame, CA).

\section{Propidium iodide (PI) staining}

To investigate the viability of MSCs, PI (Invitrogen, Carlsbad, $\mathrm{CA}$; final concentration $1.5 \mu \mathrm{M}$ ) was added to the culture dishes in the dark for $20 \mathrm{~min}$, at $37^{\circ} \mathrm{C}$. Cells were then fixed in $4 \%$ paraformaldehyde and stained with DAPI. As a positive control, a group of cells were incubated with $70 \%$ ethanol for 2 minutes and incubated with PI in the same conditions. 
Ye et al. Stem Cell Biology and Research 2016,

Table 1. Primary antibodies used in this study.

\begin{tabular}{|c|c|c|c|}
\hline Antibody & Species & Source & Dilution \\
\hline \multicolumn{4}{|l|}{ MSC markers } \\
\hline Fibronectin & Rabbit & Millipore & $1: 1,500$ \\
\hline Collagen type I & Rabbit & Millipore & $1: 500$ \\
\hline $\begin{array}{l}\text { CD } 29 \\
\text { (Integrin beta1) }\end{array}$ & Rabbit & Millipore & $1: 500$ \\
\hline $\begin{array}{l}\text { CD } 51 \\
\text { (Integrin alpha V) }\end{array}$ & Rabbit & $\begin{array}{l}\text { Dr. Thomas Joos, } \\
\text { NMI, University of } \\
\text { Tübingen }\end{array}$ & $1: 200$ \\
\hline CD90 (Thy-1.1) & Mouse & $\begin{array}{l}\text { Dr. Alan F. Williams, } \\
\text { University of Oxford }\end{array}$ & $1: 200$ \\
\hline CD54 (ICAM-1) & Mouse & Millipore & $1: 100$ \\
\hline CD11b & Mouse & Millipore & $1: 100$ \\
\hline $\mathrm{CD} 45$ & Mouse & Millipore & $1: 100$ \\
\hline CD14 & Mouse & Millipore & $1: 1,000$ \\
\hline CD44 (Hermes-1) & Rat & $\begin{array}{l}\text { Developmental Studies } \\
\text { Hybridoma Bank } \\
\text { (DSHB) }\end{array}$ & $1: 200$ \\
\hline Mouse IgG & Mouse & Millipore & $1: 100$ \\
\hline Rabbit IgG & Rabbit & Millipore & $1: 500$ \\
\hline \multicolumn{4}{|c|}{ Proliferation marker } \\
\hline BrdU & Rat & DAKO Corp. & $1: 100$ \\
\hline \multicolumn{4}{|l|}{ Neural markers } \\
\hline Nestin & Mouse & DSHB & $1: 200$ \\
\hline III $\beta$-tubulin (TuJ1) & Mouse & $\mathrm{R} \& \mathrm{D}$ systems & $1: 200$ \\
\hline MAP2ab & Mouse & Sigma & $1: 200$ \\
\hline GFAP & Mouse & Fisher Scientific & $1: 500$ \\
\hline RIP & Mouse & DSHB & $1: 1,000$ \\
\hline
\end{tabular}

CD: Cluster of differentiation; MAP2ab: Microtubule associated protein 2ab; GFAP: Glial fibrillary acidic protein; RIP: Receptor interacting protein

Under this control condition all MSCs were PI-labeled.

\section{Adipogenesis}

A mesenchymal stem cell Adipogenesis kit (Cat. No. SCR 020; Millipore, Billerica, MA) was used to generate adipocytes from the isolated rat MSCs. The induction protocol as specified in the datasheet was applied. Briefly, MSCs were plated at a density of 60,000 cells per well in a 24-well culture plate. When the cells reached $100 \%$ confluency, adipogenesis induction medium was added into the wells. Induction and maintenance medium was changed every two days for 21 days. MSC cultures were fixed in $4 \%$ paraformaldehyde for 30 minutes at room temperature and rinsed. Oil Red O Solution was added for 50 min to stain adipocytes containing lipid droplets. Cell nuclei were stained with hematoxylin solution (15 minutes). Rat cortical astrocytes [32] were subjected to the same conditions and used as a negative control.

\section{Osteogenesis}

MSCs were induced to differentiate into osteogenic lineages using a MSC Osteogenesis kit (Cat. No. SCR 028; Millipore) as per the protocol specified in the datasheet provided. Briefly, each well of a 24-well plate was coated with vitronectin and collagen in sterile PBS to yield a final concentration of $12 \mu \mathrm{g} /$ $\mathrm{mL}$ for each extracellular matrix (ECM) molecule and MSCs plated at a density of 60,000 cells per well. When the cells were $100 \%$ confluent, osteogenesis induction medium was added into the wells. Induction medium was changed every $2 \sim 3$ days for 14 days. Osteocytes were fixed in iced cold $70 \%$ ethanol for 1 hour at room temperature. Alizarin Red Solution was added for 30 minutes in order to stain osteocytes containing calcium deposits. Astrocytes subjected to the same conditions were used as a negative control.

\section{Co-Culture of MSCs with AHPCs}

Adult hippocampal progenitor cells (AHPCs, provided by F. Gage, Salk Institute, La Jolla, CA) [33] were co-cultured with MSCs. For contact co-cultures (CCC) MSCs were plated onto glass coverslips coated with poly-L-ornithine $(100 \mu \mathrm{g} / \mathrm{ml}$ in sterile water) and laminin ( $10 \mu \mathrm{g} / \mathrm{ml}$ in Earle's Balanced Salt Solution) (referred to as: poly-L-ornithine/laminin-coated coverslips) at a density of 7,000 cells per well, in 6 well culture plates (4 coverslips/well). After $24 \mathrm{hr}$. AHPCs were plated onto the monolayers of MSCs at 20,000 cells per well. Cocultures were maintained in co-culture media, consisting of AHPC differentiation media in a 7:3 mixture with MSC growth media (with $10 \% \mathrm{FBS})$. Transwell inserts $(0.4 \mu \mathrm{m}$ semi-porous membrane inserts; Corning, Inc., Corning, NY) were used to establish non-contact co-cultures (NCCC) of MSCs and AHPCs growing together in the absence of physical contact. MSCs were plated onto the insert membrane and the following day, AHPCs were plated onto poly-L-ornithine/laminin-coated coverslips in the lower chamber culture well at 20,000 cells per well. The co-cultures were maintained in co-culture media. As controls, AHPCs and MSCs were plated separately in the same co-culture medium at their respective densities. Cells were maintained at $37^{\circ} \mathrm{C}$ in a $5 \% \mathrm{CO}_{2} / 95 \%$ air atmosphere. Coculture media was refreshed every 2-3 days. After 7 days the cells were fixed in $4 \%$ paraformaldehyde and immunostained as described in the following immunocytochemistry section.

\section{Immunocytochemistry}

For immunolabeling, cells were fixed in $4 \%$ paraformaldehyde for $20 \mathrm{~min}$. Fixed cells were rinsed in PBS and then incubated in blocking solution containing $5 \%$ normal donkey serum, $0.4 \%$ bovine serum albumin (BSA; Sigma), and $0.2 \%$ Triton $\mathrm{X}-100$ (Fisher Scientific), followed by incubation with primary antibodies overnight at $4^{\circ} \mathrm{C}$. A panel of cell-type specific antibodies (Table 1) from a Rat Mesenchymal Stem Cell Characterization kit (Cat. No. SCR018; Millipore) was used to characterize MSCs. Primary antibodies and their dilutions are listed in Table 1. After rinsing in PBS, cells were incubated in the secondary antibodies conjugated to Cy3 diluted at 1:500 (Jackson ImmunoResearch, West Grove, PA). Cell nuclei were stained with DAPI, diluted at 1:2,000 in PBS and applied for 30 
Ye et al. Stem Cell Biology and Research 2016,

http://www.hoajonline.com/journals/pdf/2054-717X-3-3.pdf

minutes. Preparations were rinsed and then mounted onto microscope slides using an antifade mounting medium (Gel Mount; Biomeda Corp., Foster City, CA). Negative controls were performed in parallel by omission of the primary antibodies. No antibody labeling was observed in the controls.

\section{Quantification of neurite outgrowth}

A quantitative analysis of neurite outgrowth from AHPCs was performed by determining the number of neurite branches from cells with neuronal morphologies immunolabeled with the TuJ1 antibody (TuJ1-IR). The extent of neurite arborization was assessed using a Sholl analysis $[34,35]$ plugin to $\mathrm{NIH}$ ImageJ [36]. The concentric circles plugin for Sholl analysis creates concentric circles with radii 10,20 , and $30 \mu \mathrm{m}$ from the center of the cell soma. The number of neurite intersections with each circle was then manually counted. Analysis was performed in masked fashion.

\section{Imaging and statistics}

Phase contrast images were taken using a Nikon Diaphot inverted microscope with a CCD camera (Megaplus; Model 1.4; Kodak Corp., San Diego, CA) connected to a frame grabber (Megagrabber; Perceptics, Knoxville, TN, in a Macintosh computer; Apple Computer, Cupertino, CA) using NIH Image 1.58VDM software (Wayne Rasband, National Institutes of Health, Bethesda, MD). Images of MSCs and AHPCs labeled with antibodies were captured using a Nikon Microphot FXA fluorescence microscope equipped with a Retiga 2000R digital camera controlled by QCapture software (QImaging, Surrey, British Columbia, Canada). Figure plates were prepared using Photoshop CS2. Data were reported as means \pm standard error of the mean (S.E.M.). Statistical analysis was performed using GraphPad PRISM (ver. 3.0). All tests were two-tailed tests and $p$ values less than an alpha of 0.05 were considered significantly different.

\section{Results}

Isolation and Characterization of Brown Norway Rat MSCs

\section{Culture of MSCs}

Mesenchymal stem cells (MSCs) from male and female Brown Norway rats were isolated from the bone marrow by their characteristic adherence to a plastic culture surface. The adherent MSCs were cultured as a monolayer and passaged when they reached 70 80\% confluence. As illustrated in Figure 1, the MSCs showed a typical spindle-shape and fibroblastlike morphology. At early passage, small and slender MSCs were predominantly observed in the population. At later passages, we observed a relatively larger ratio of cells with large and flattened morphology compared to that of early passage cells (Figure 1).

\section{Characterization of MSCs}

Characterization of the MSCs was performed using immunocytochemistry with a panel of negative and positive antibody

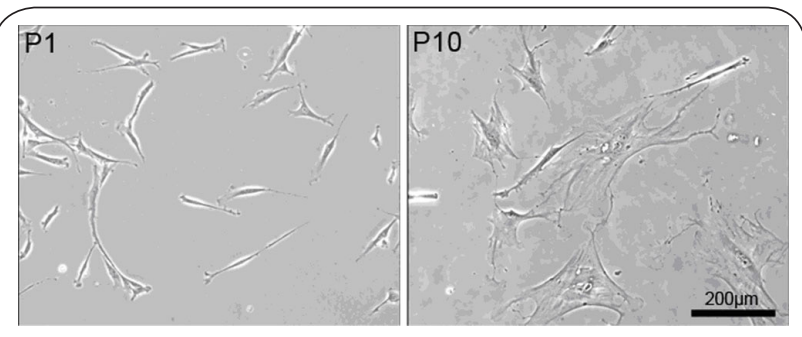

Figure 1. Phase contrast images of MSCs (male) at initial isolation (Passage 1, P1) and after 10 passages (P10). MSCs isolated from BN-rat bone marrow were cultured as a monolayer on plastic culture plates. Both small, rapidly self-renewing MSCs and larger, more mature MSCs were observed. MSCs had a spindle-shape and fibroblast-like morphology. In later passages, a greater proportion of cells displayed a flattened, fibroblast-like morphology. Scale bar $=200 \mu \mathrm{m}$.

markers for rat MSCs (Table 1). After culturing for 4 or 5 passages, the vast majority of the adherent bone marrow-derived cells were specifically immunoreactive with antibody markers for MSCs (CD29, CD51, CD54, CD90, fibronectin, and collagen type I) (Figures 2A-2F). Furthermore, no MSCs showed specific immunoreactivity for the negative markers (CD11b, CD14, CD44, and CD45; Figures 2G-2J) and antibody controls (mouse IgG

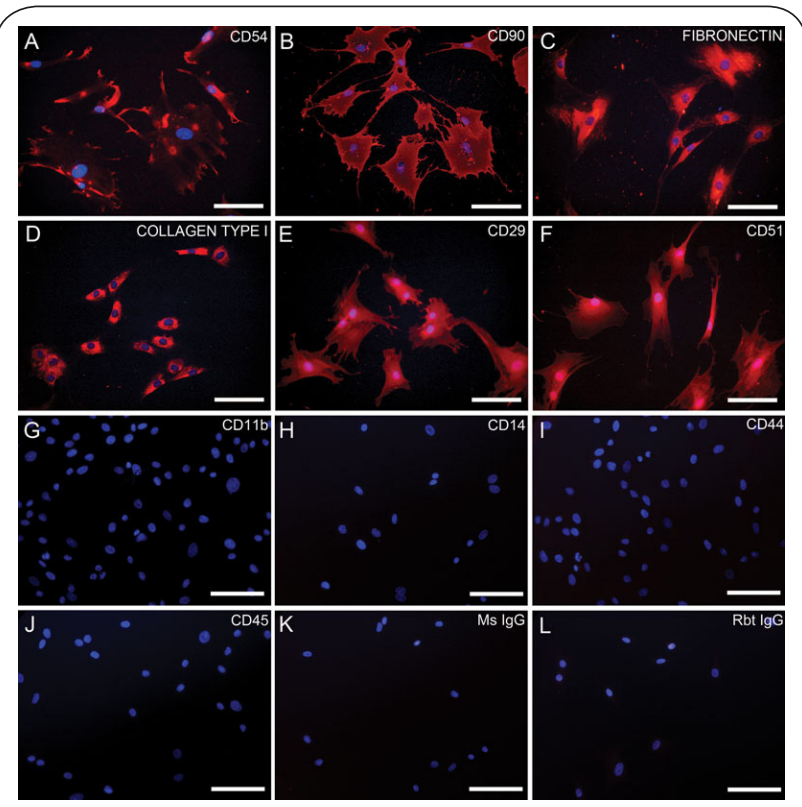

Figure 2. Characterization of MSCs immunostained with a panel of phenotypic markers. (A-F) Bone marrowderived cells stained with a panel of MSC specific -positive antibody markers. No specific staining with MSC negative antibodies (CD11b, CD14, CD44 and CD45) was detected. (CD14-present on leukocytes; CD44-present on leukocytes and endothelial cells; CD45-present on monocytes and macrophages). (K and $\mathbf{L}$ ) No staining was found with mouseand rabbit-IgG secondary antibodies, negative controls. Scale bar $=50 \mu \mathrm{m}(\mathbf{A}$ through $\mathbf{L})$. 
Ye et al. Stem Cell Biology and Research 2016,

and rabbit lgG; Figures 2K-2L). (See also Supplementary Figure 1. For the characterization of MSCs isolated from a female rat.). These MSCs were also screened with a panel of antibodies against neural antigens to investigate their potential expression of endogenous neural-lineage markers. About $30 \%$ of MSCs were nestin-immunoreactive (Supplementary Figure 2) and no specific staining was found for TuJ1, MAP2ab, or GFAP antibodies (data not shown).

\section{MSC growth rate and proliferation}

The growth and proliferation (population doubling time (PDT)) of the MSCs were analyzed at passages 1, 4, 9, and 15 (Table 2). MSCs from female rats ( 9 ) showed values of PDT (hr), $23.74( \pm 7.71), 37.01( \pm 4.93), 25.76( \pm 7.07)$, and 28.73 $( \pm 7.74)$ at $P 1,4,9$, and 15 , respectively. MSCs isolated from male rats $(\hat{\jmath})$ displayed a similar range of growth rates; 17.68 $( \pm 4.14), 29.67( \pm 2.16), 25.5( \pm 2.63)$, and $23.43( \pm 2.56)$ at $P 1,4$, 9 , and 15 , respectively. There were no significant differences between the different passages/or between MSCs, isolated from male versus female Brown Norway rats. In addition, a BrdU assay was performed to examine the proliferation of MSCs with increasing passage number (Table 3). MSCs were exposed to $5 \mu \mathrm{M}$ BrdU for 24 hours. More than $80 \%$ of MSCs

Table 2. Population doubling time (PDT) for MSCs (male and female) at different passages.

\begin{tabular}{lllll}
\hline PDT (hrs) & P1 & P4 & P9 & P15 \\
\hline MSC (ㅇ) & 23.74 & 37.01 & 25.76 & 28.73 \\
& \pm 7.71 & \pm 4.93 & \pm 7.07 & \pm 7.74 \\
\hline MSC (ठ̊) & 17.68 & 29.67 & 25.50 & 23.43 \\
& \pm 4.14 & \pm 2.16 & \pm 2.63 & \pm 2.56 \\
\hline
\end{tabular}

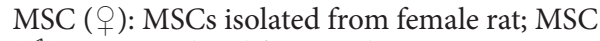
$(\widehat{)})$ : MSCs isolated from male rat.

(Values; Mean \pm S.E.M.; Sample size, $\mathrm{N}=3$ )

Table 3. BrdU assay.

\begin{tabular}{|c|c|c|c|c|}
\hline$\%$ BrdU & P1 & P4 & P9 & P15 \\
\hline \multirow[t]{2}{*}{ MSC (ㅇ) } & 93.00 & 88.67 & 83.67 & 83.33 \\
\hline & \pm 2.52 & \pm 3.84 & \pm 7.17 & \pm 4.10 \\
\hline \multirow[t]{2}{*}{$\operatorname{MSC}\left(\delta^{\Uparrow}\right)$} & 89.33 & 54.76 & 84.33 & 85.33 \\
\hline & \pm 4.37 & \pm 5.22 & \pm 1.45 & \pm 5.78 \\
\hline
\end{tabular}

MSC ( $(+)$ : MSCs isolated from female rat; MSC $(\widehat{)})$ : MSCs isolated from male rat.

(Values; Mean \pm S.E.M.; Sample size, $\mathrm{N}=3$ )

were BrdU-IR at most passages. A significantly lower percentage $(54.76 \%)$ of BrdU-labeled cells was observed for the MSCs (ठ) at P4, although the BrdU percentages were essentially equal between the MSC populations at all other time points.

\section{Cell viability}

Analysis of cell viability was performed using a propidium iodide (PI) assay. Cells with compromised membrane integrity (e.g., unhealthy or dead cells) are differentiated from healthy and viable cells due to the fluorescence of PI, which binds to DNA in the nucleus of dead cells. MSCs maintained under normal growth conditions were not labeled by the $\mathrm{PI}(0 \%$ PI-labeled, Supplementary Figure $3 \mathrm{~A}, \mathrm{~N}=3$ ). As a PI reagent control, MSCs were incubated with $70 \%$ ethanol, resulting in 100\% PI-labeled MSCs (Supplementary Figure 3B; N=3).

\section{Differentiation of MSCs into mesodermal lineages}

The multipotential nature of the MSCs was investigated by examining their ability to differentiate into adipogenic and osteogenic lineages. MSCs differentiated into adipocytes 21 days after adipogenic induction. Lipid droplets in adipocytes derived from MSCs following induction were stained with Oil Red O solution (Figures $3 \mathrm{~A}$ and $3 \mathrm{~B}$ ). MSCs subjected to osteogenic induction conditions for 14 days were visualized with Alizarin red solution. Amorphous deposits of calcium were stained red, demonstrating osteogenic differentiation ability of the MSCs (Figures 3C and 3D). For both differentiation paradigms (adipogenic and osteogenic) astrocytes were used as a negative control and were subjected to the induction protocols and resulted in no Oil Red $\mathrm{O}$ or Alizarin red staining, respectively (Supplementary Figures $4 \mathrm{C}$ and $4 \mathrm{~F}$ ). These results indicate that the MSC populations isolated from Brown Norway rat bone marrow are multipotent MSCs.

\section{Co-culture of MSCs with AHPCs}

To examine the possibility that MSCs can influence the proliferation and differentiation of adult neural progenitor cells,

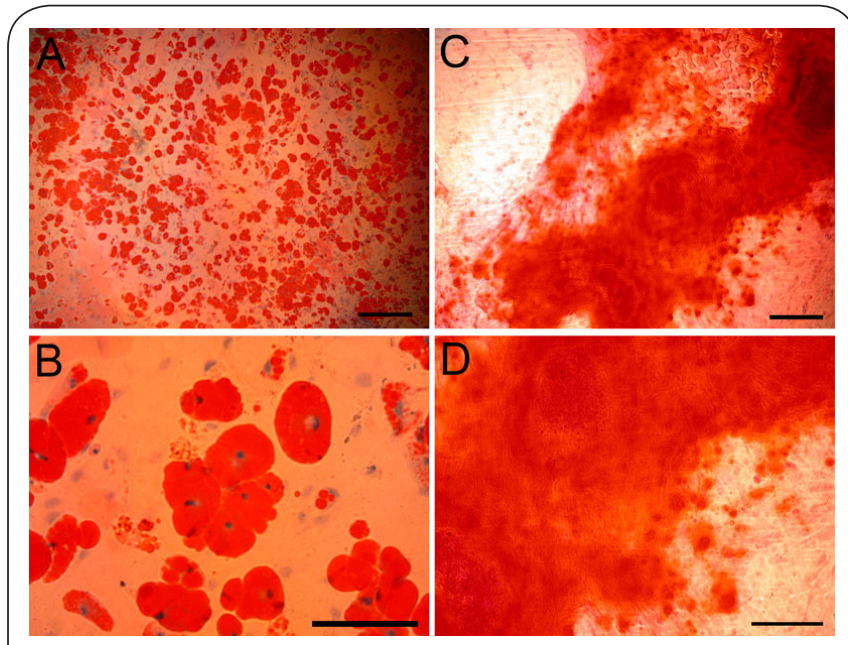

Figure 3. Differentiation of MSCs-Adipogenesis and osteogenesis. (A-B) MSCs were cultured in adipogenic induction media for 21 days. Adipocytes differentiated from MSCs were stained with Oil Red O Solution. Lipid droplets in adipocytes were clearly observed. Cell nuclei were stained with Hematoxylin solution. (C-D) For osteogenesis, MSCs were differentiated in osteogenic induction media for 14 days. Osteocytes containing calcium deposits were visualized with Alizarin Red Solution. (Scale bars-A and C: $300 \mu \mathrm{m}$; B: 100 $\mu \mathrm{m} ; \mathrm{D}: 200 \mu \mathrm{m})$. 
Ye et al. Stem Cell Biology and Research 2016,

we established co-cultures of adult hippocampal progenitor cells (AHPCs) with MSCs. Upon growth factor withdrawal, the AHPCs have the capacity to differentiate into morphologically distinct neuronal cells, oligodendrocytes and astrocytes [32]. To delineate possible contact-mediated and/or soluble inducing activities associated with the MSCs, the AHPCs were differentiated in parallel under different culture conditions: (1) AHPCS cultured alone, (2) AHPCs cultured with MSCs in noncontact co-culture conditions (NCCC), and (3) AHPCs co-cultured in physical contact with the MSCs (contact co-culture condition, CCC). The AHPCs express green fluorescent protein (GFP) which facilitated their identification when co-cultured with the non-GFP-expressing MSCs (Figure 4). After 7 days, cultures were fixed and immunostained to examine cell proliferation

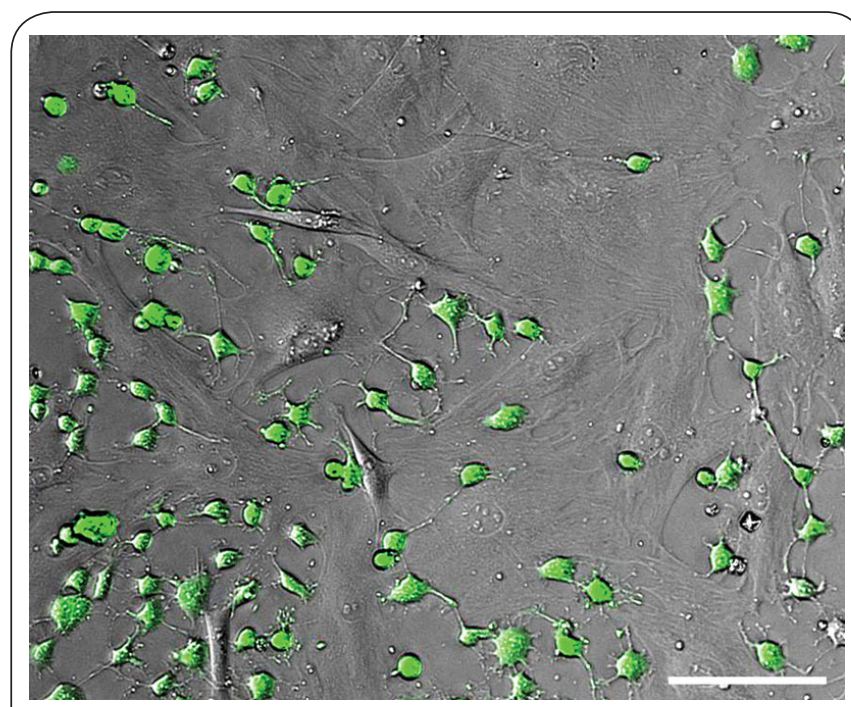

Figure 4. Contact co-culture (CCC) of AHPCs with MSCs. AHPCs were co-cultured in physical contact with the MSCs. The GFP-expressing AHPCs, are easily identified from the non-GFP-expressing MSCs. Image was captured at 3 days in vitro (DIV) following establishment of the co-culture. Fluorescence image of GFP-expressing AHPCs merged with phase contrast image. (Scale bar $=50 \mu \mathrm{m})$.

(BrdU-IR) and differentiation. A BrdU incorporation analysis revealed no significant differences in the overall percentages of AHPCs immunoreactive with the BrdU antibody (Table 4). To investigate differentiation, the percentages of AHPCs immunoreactive for neuronal (TuJ1-IR) or oligodendrocyte (RIP-IR) markers was determined. When cultured alone, $21 \%$ of the AHPCs were TuJ1-IR and $59 \%$ RIP-IR (Table 4). When co-cultured with MSCs under noncontact conditions (NCCC) $\sim 23 \%$ of the AHPCs were TuJ1-IR and $\sim 29 \%$ RIP-IR. When AHPCs were co-cultured in physical contact (CCC) with MSCs $\sim 19 \%$ were TuJ1-IR and 55\% RIP-IR. No significant differences in AHPC differentiation into TuJ1-IR neurons were observed across the three culture conditions. Although the percentage of AHPCs immunolabeled for RIP was on average lower
Table 4. Differentiation of AHPCs after Co-culture with MSCs.

\begin{tabular}{llll}
\hline & AHPC & NCCC & CCC \\
\hline TuJ1 & 21.46 & 23.11 & 19.74 \\
& \pm 8.77 & \pm 4.47 & \pm 6.92 \\
\multirow{2}{*}{ RIP } & 59.15 & 29.45 & 54.61 \\
& \pm 13.04 & \pm 8.10 & \pm 7.98 \\
\multirow{2}{*}{ BrdU } & 36.89 & 29.76 & 38.23 \\
& \pm 10.22 & \pm 7.65 & \pm 10.94 \\
\hline
\end{tabular}

(Values; Mean \pm S.E.M.; Sample size, $\mathrm{N}=3$ )

in the NCCC condition, there were no significant differences between the culture groups (Table 4). The MSCs only group was not included in the data analysis due to difficulties in imaging of the cells growing on the membrane inserts.

Morphological differences in TuJ1- and RIP-IR AHPCs were noted when comparing AHPCs cultured alone versus the co-culture groups (CCC and NCCC). Co-culture with MSCs stimulated neurite outgrowth of neuronal AHPCs (TuJ1-IR). TuJ1-IR AHPCs, in both NCCC and CCC conditions, showed longer and highly branched neurites when compared to the AHPCs only condition (Figure 5). Quantitative assessment was performed by Sholl analysis as illustrated in Figure 5D. Significant differences in the number of neurite intersections at a radius of $20 \mu \mathrm{m}$ (AHPCs only vs. NCCC and AHPCs only vs. $C C C ; p$ value $<0.05$ ) were observed. These results indicate that MSCs and or MSC-derived factors played a significant role in the morphological differentiation of AHPCs by promoting neurite outgrowth during the co-culture conditions. Furthermore, physical contact (CCC) between the MSCs and AHPCs during co-culture resulted in thicker neuronal processes and increased complexity, compared to that of the NCCC. In addition to influencing neurite outgrowth from TuJ1-IR cells, MSC co-cultures also appeared to influence the branching of RIP-IR cells. Both in NCCC and CCC conditions, RIP-IR cells were more highly branched with a larger area of arborization compared to that of the AHPCs only group. In addition, the primary processes of the RIP-IR AHPCs in the CCC group appeared to be thicker, compared to those of the other groups (Indicated with an arrow head; Figure 6). However, a quantitative analysis of the morphology of RIP-IR cells was not possible due to the processes of RIP-IR cells being too close or overlapping to be distinguishable from those of adjacent cells. Taken together, these results indicate that co-cultures of MSCs with the AHPCs promoted the morphological differentiation of neuronal and glial cells differentiating from AHPCs.

\section{Discussion}

Bone marrow-derived MSCs possess considerable potential towards development of cell-based therapeutics. The present study isolated and characterized bone marrow-derived MSCs isolated from male and female Brown Norway rats ( 0 and + ), 


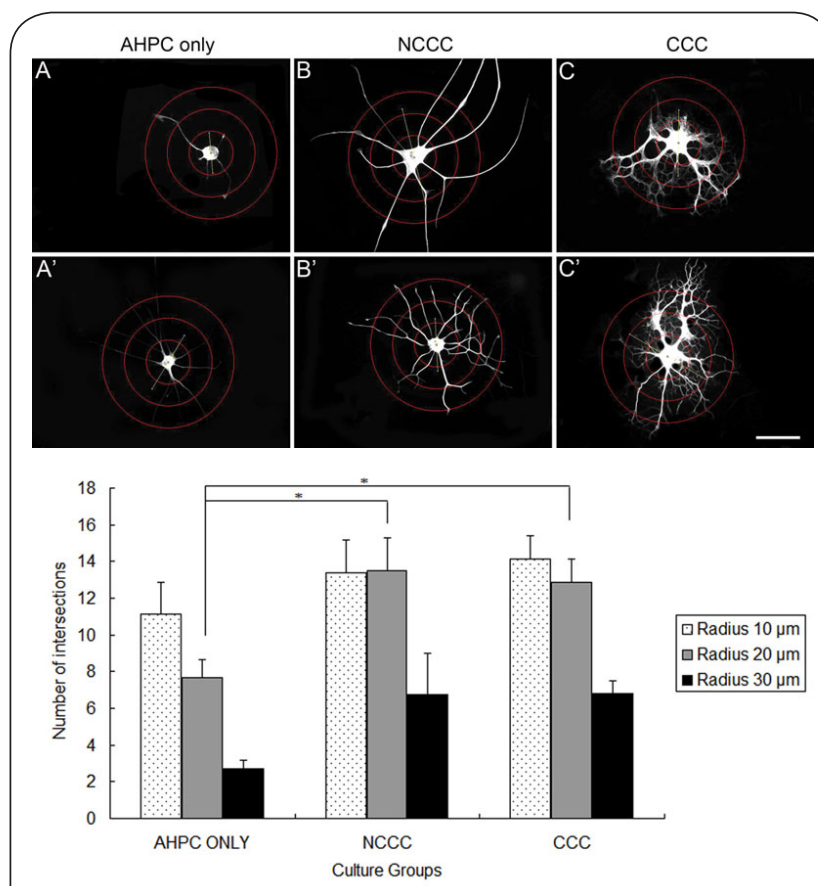

Figure 5. Sholl analysis for the quantification of neurite outgrowth of TuJ1-IR AHPCs.

AHPCs, after 7 days co-culture with MSCs, were immunostained with a neuronal marker (TuJ1). Two representative images from each group are presented, from AHPCs only (A, $\left.\mathbf{A}^{\prime}\right)$, NCCC (B, B'), and CCC $(\mathbf{C}$, C') groups. Sholl analysis was performed to measure the extent of neurite growth and branching from TuJ1-IR cells. Three concentric circles (radii 10,20, and $30 \mu \mathrm{m}$ from the center of the cell soma) were superimposed onto TuJ1IR cells. The number of neurite intersections with each concentric circle was counted. AHPCs in both NCCC and CCC conditions displayed increased neurite outgrowth compared to that of AHPCs only group. Abbreviations: AHPC, adult hippocampal progenitor cells; NCCC, noncontact co-culture; CCC, contact co-culture. (Scale bar = $20 \mu \mathrm{m}$; applied from A through C'). D. Neurite complexity summary bargraph. Neurite outgrowth of AHPCs after coculture with MSCs. Neurite outgrowth of neuronal AHPCs (TuJ1-IR) was quantified by performing Sholl analysis. After 7 days co-culture with MSCs, there were significantly increased number of neurite intersections at a radius of 20 $\mu \mathrm{m}$ (AHPCs only vs. NCCC and AHPCs only vs. CCC). Error bars $=$ S.E.M.; ${ }^{*}$ :p value $<0.05$.

a commonly used strain for biomedical research $[20,23,24,37,38]$. MSCs were successfully isolated from the bone marrow and were cultured for 20 passages displaying stable and consistent growth rates. Immunostaining with a panel of MSC positive- and negative- antibody markers demonstrated that the identity of these populations of cells were consistent with MSCs, lacking hematopoietic cell lineages. The PDTs for these MSCs was about a day, indicating a relatively rapid cell proliferation rate. Furthermore, BrdU analysis indicated that most MSCs maintained a proliferative capacity throughout the passages examined. When maintained under optimal

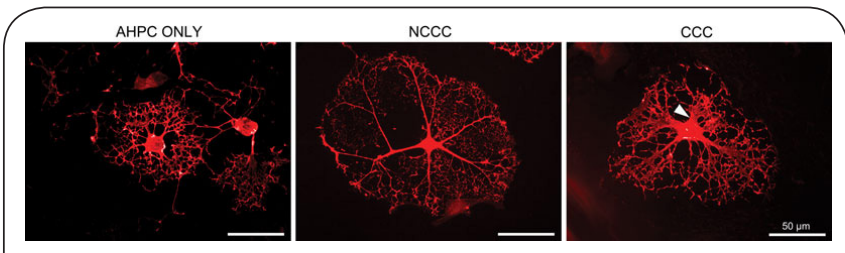

Figure 6. Oligodendrocyte differentiation of AHPCs following co-culture with MSCs. AHPCs were co-cultured with MSCs for 7 days and immunostained with a oligodendrocyte marker, RIP. Nuclei were stained with DAPI. AHPCs in both NCCC and CCC conditions showed a more highly branched morphology and in general, a larger area of processes than that of the AHPCs only group. Also, in CCC condition, the thickness of primary processes was generally found to be greater than that of other groups (Indicated with an arrow head). Scale bar $=50 \mu \mathrm{m}$.

growth conditions, cell viability was high, with no PI staining indicative of cell death. In addition, the multipotential nature of these MSCs was demonstrated based on their ability for adipogenesis and osteogenesis. The isolation and characterization of these Brown Norway rat MSCs will broaden the availability of MSC lines for autologous and syngeneic transplant studies towards development of experimental strategies for treating neurodegenerative conditions. When co-cultured with adult hippocampal progenitor cells (AHPCs), the MSCs provided significant stimulation of neurite outgrowth. The MSC associated activity is in part likely mediated via soluble cues.

The Brown Norway rat MSCs isolated and characterized in this study initially displayed heterogenous morphologies, consisting of spindle-shaped and fibroblast-like cells as reported previously [39]. The fibroblastic cell morphology became more prominent over time with continued subculturing. The morphological characteristics of these MSCs are consistent with other rodent strains of MSCs $[18,31,40]$.

Cell phenotyping was conducted using a panel of MSC positive- (fibronectin, collagen type I, CD29, CD54, CD51 and CD90) and negative-(CD11b, CD14, CD44 and CD45) antibodies for rat MSCs. In all experiments the MSCs were immunoreactive for the positive markers and no detectable immunolabeling for the negative MSC markers was observed, suggesting that the population lacked hematopoietic lineage cells, consistent with a highly pure population of MSCs.

The growth and proliferation of MSCs were studied and compared between cells isolated from male and female donor rats to examine the possibility of intrastrain sex differences. With increasing passages, MSCs showed some variability in population doubling time (18-37 PDT (hours)) though the average PDTs were not significantly different from early to late passages. Furthermore, no significant differences of PDTs were found between male- and female-MSCs. The results of BrdU assay also suggest that most MSCs were in an actively replicating state. This property would be a benefit to meet the needs of generating a large number of cells for scientific research and preclinical applications. Unexpectedly, a low 
Ye et al. Stem Cell Biology and Research 2016,

http://www.hoajonline.com/journals/pdf/2054-717X-3-3.pdf

doi: 10.7243/2054-717X-3-3

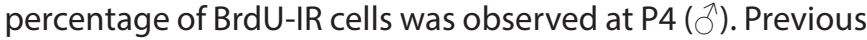
studies reported reduced proliferation and/or growth-arrest in rat MSCs at passage 4 or 5 [41-43]. Population doubling time at P4 ( $\left({ }^{\lambda}\right)$ in the present study, however, was not significantly different from other passages and only the ratio of BrdU-IR cells decreased. A possible reason may be that a larger proportion of MSCs may linger in G2, M, or G0 phases compared to cells at other passages. The PDT value of these Brown Norway rat MSCs was relatively short compared to those of other strains of rat (Fisher, Lewis, Sprague-Dawley, and Wistar) which showed approximately 2-4 days PDT [18]. However, consistent with our data, Karaoz and colleagues [31] reported 19-41 hours PDT for Wistar rat MSCs. Nonetheless, it is clear that growth characteristics of MSCs, in fact, can vary depending on the species, strains, passages, and the regions from which cells were isolated $[\mathbf{9 , 4 0}$. It is possible that such differences may be due to the age of the animals, techniques used for cell isolation and culture, as well as general health conditions between individual animals.

The multipotential ability of these MSCs was demonstrated by their differentiation into adipocytes and osteocytes in vitro. A growing body of literature indicates that MSCs possess phenotypic plasticity and are able to generate myoblasts, tendon/ ligament fibroblasts, adipocytes, osteocytes, and chondrocytes [5]. Karaoz et al., [31] demonstrated endogenous expression of osteo-, myo-, and neuro-genic markers, which supports the plasticity of rat MSCs to differentiate into various cell types. A small proportion of Brown Norway rat MSCs were immunolabeled with a nestin antibody, a neural stem cell marker. A complex filamentous network of immunolabeling was observed in these MSCs, consistent with nestin intermediate filament labeling. Nevertheless, the ability of MSCs to transdifferentiate into neural cells remains a complicated and controversial issue requiring additional studies.

A clearly emerging theme for use of MSCs as cellular vehicles for neural repair is their neurogenic, neuroprotective and immunomodulatory activities. MSCs have the ability to synthesize and secrete a variety of biomolecules such as neurotrophic factors, cytokines, and growth factors $[44,45]$. A number of studies have demonstrated that such factors can enhance neural cell proliferation, differentiation, and survival [46-52]. Furthermore, MSCs have been shown to secrete neurogenic factors including brain-derived neurotrophic factor (BDNF), glial cell line-derived neurotrophic factor (GDNF), ciliary neurotrophic factor (CNTF), and neurotrophin-3 (NT-3) $[\mathbf{4 4 , 5 3 , 5 4 ]}$. The present study investigated the ability of these MSCs to influence the differentiation of adult rat hippocampal derived progenitor cells (AHPCs). These multipotent AHPCs are capable of differentiating into neurons, oligodendrocytes and astrocytes [55]. Two types of co-cultures were established to exam cell-cell associated activities, as well as secreted soluble factors from the MSCs. No significant differences in the proportion of AHPC differentiation towards a neuronal (TuJ1-IR) or glial (RIP-IR) cell type were observed in the co- cultures of MSCs with the AHPCs. However, morphological differentiation of both neuronal and oligodendrocyte-like AHPCs was evident. Both co-culture configurations (NCCC and CCC) resulted in significant increases in neurite outgrowth and complexity on neuronal AHPCs (TuJ1-IR cells) when compared to AHPCs differentiating on their own. Neurotrophic factors such as BDNF induce neurite outgrowth from neuronal cells and neural progenitors $[\mathbf{5 6 , 5 7}]$ and this may in part account for neurite growth promoting activity observed in the co-cultures with MSCs. Further studies will be required to examine what types of receptors for biomolecules are expressed on AHPCs. Interestingly, when co-cultured in direct contact with the MSCs (CCC) the AHPCs displayed an even more pronounced complexity of neurites than that of NCCC. Thus, it is likely that cell-cell interactions mediated by cell adhesion molecules and/ or extracellular matrix molecules (ECM) also play important roles in the MSC neurite outgrowth promoting activity [58-61]. In the present study, we showed that the expression of ECM molecules (fibronectin and collagen type I) and CD29 (integrin $\beta_{1}$ ) on MSCs. It is well-documented that fibronectin and collagen type I interact with integrin $\alpha_{5} \beta_{1}$ and $\alpha_{2} \beta_{1}$, respectively [62]. Moreover, a previous study reported the expression of integrins $\left(a_{2} a_{5}\right.$ and $\left.\beta_{1}\right)$ and ECM molecules (fibronectin and laminin) on the AHPCs [63]. Thus, it is possible that physical contact between MSCs and AHPCs would allow cellular interactions mediated through integrin-ECM signaling to stimulate neurite outgrowth. Interactions between the ECM and integrins activate signaling pathways that modulate the dynamics of the cytoskeletons [64], and the changes of cytoskeletal proteins involved in microtubule and actin filaments contribute to the formation and regulation of neurite outgrowth.

MSCs possess considerable therapeutic potential due to a number of advantages, including relative ease of isolation, plasticity, proliferative capacity, paracrine activity, various sources for isolation, and differentiation potential into multiple lineages. Clinical studies using human bone marrowmesenchymal cells as allografts have demonstrated practical use of MSCs for tissue-repair [17]. MSCs can directly or indirectly affect the outcome after transplantation in vivo because of their ability to secrete various factors such as angiogenic, anti-apoptotic, proliferation-stimulating factors, and neurotrophic factors $[\mathbf{4 4 , 4 5 , 6 5 ]}$. Such utility for MSCs has also been suggested by MSC transplantation into the eyes of experimental glaucoma models followed by subsequent neuroprotective effects on the retinas [66]. MSCs, furthermore, can be genetically modified to express bioactive molecules so they can act as a delivery vehicle for the factors in vivo. BDNF-secreting MSCs transplanted into neurodegenerative eyes provided notable preservation of the host retinas morphologically and functionally [67].

\section{Conclusions}

This study indicates that MSCs from Brown Norway rats have the potential to be a cell source for stem cell-based therapies 
Ye et al. Stem Cell Biology and Research 2016,

due to their fast and consistent proliferation, and ability for multipotent differentiation. Furthermore, these MSCs promoted morphological differentiation of neuronal-like as well as oligodendrocyte-like brain stem/progenitor cells and may provide an added benefit for use in developing strategies for nervous system rescue and repair.

\section{List of abbreviations}

AHPCs: Adult hippocampal progenitor cells

aMEM: Alpha minimum essential medium

BDNF: Brain-derived neurotrophic factor

BrdU: 5-bromo-2-deoxyuridine

CCC: Contact co-culture

CNTF: Ciliary neurotrophic factor

DAPI: 4', 6-diamidino-2-phenylindole, dilactate

ECM: Extracellular matrix

GDNF: Glial cell line-derived neurotrophic factor

MM: Maintenance media

MSCs: Mesenchymal stem cells

NCCC: Non-contact co-culture

NT-3: Neurotrophin-3

PBS: Phosphate-buffered saline

PDT: Population doubling time

PI: Propidium iodide

TCPS: Tissue culture polystyrene

\section{Additional files}

Supplementary Figure 1
Supplementary Figure 2
Supplementary Figure 3
Supplementary Figure 4

Competing interests

The authors declare that they have no competing interests.

Authors' contributions

\begin{tabular}{|l|c|c|c|c|}
\hline Authors' contributions & EY & SSC & MZK & DSS \\
\hline Research concept and design & $\checkmark$ & -- & -- & $\checkmark$ \\
\hline Collection and/or assembly of data & $\checkmark$ & $\checkmark$ & $\checkmark$ & -- \\
\hline Data analysis and interpretation & $\checkmark$ & -- & -- & $\checkmark$ \\
\hline Writing the article & $\checkmark$ & -- & -- & $\checkmark$ \\
\hline Critical revision of the article & $\checkmark$ & -- & -- & $\checkmark$ \\
\hline Final approval of article & $\checkmark$ & $\checkmark$ & $\checkmark$ & $\checkmark$ \\
\hline Statistical analysis & $\checkmark$ & -- & -- & -- \\
\hline
\end{tabular}

\section{Acknowledgement}

The authors would like to thank Dr. Roxanne Reger at Texas A\&M Health Science Center College of Medicine for providing advice and the protocol for rat bone marrow isolation, and Dr. Fred H. Gage at the Salk Institute for the gift of the AHPCs. lowa State University undergraduates, Amy Harvey and Pat Poston assisted with data collection. Drs. Svitlana Zbarska, Anup Sharma, and Melih Dagdeviren provided comments on the manuscript. None of the authors have any conflict of interest to declare. This work was supported by the National Eye Institute (NIH) \#1R01E4019294; the Stem Cell Research Fund; and the Genetics, Development and Cell Biology Department.

\section{Publication history}

Editors: Kameshwar P Singh, University of Rochester, USA.

Andreas K Nüssler, University of Tubingen, Germany.

Received: 07-Oct-2016 Final Revised: 11-Nov-2016

Accepted: 25-Nov-2016 Published: 09-Dec-2016

\section{References}

1. Arthur A, Zannettino A and Gronthos S. The therapeutic applications of multipotential mesenchymal/stromal stem cells in skeletal tissue repair. J Cell Physiol. 2009; 218:237-45. | Article | PubMed

2. Joe AW and Gregory-Evans K. Mesenchymal stem cells and potential applications in treating ocular disease. Curr Eye Res. 2010; 35:941-52. Article | PubMed

3. Simmons PJ, Przepiorka D, Thomas ED and Torok-Storb B. Host origin of marrow stromal cells following allogeneic bone marrow transplantation. Nature. 1987; 328:429-32. | Article | PubMed

4. Sueblinvong $V$ and Weiss DJ. Cell therapy approaches for lung diseases: current status. Curr Opin Pharmacol. 2009; 9:268-73. | Article | PubMed Abstract | PubMed FullText

5. Ohishi M and Schipani E. Bone marrow mesenchymal stem cells. J Cell Biochem. 109:277-282. | Article

6. Sandquist EJ, Uz M, Sharma AD, Patel BB, Mallapragada SK and Sakaguchi DS. Stem cells, bioengineering and 3-D scaffolds for nervous system repair and regeneration. In: Neural Engineering: from Advanced Biomaterials to 3D Fabrication Techniques. Edited by Zhang LG, Kaplan D: Springer. 2016. I Book

7. Hu Y, Liao L, Wang $Q$, Ma L, Ma G, Jiang $X$ and Zhao RC. Isolation and identification of mesenchymal stem cells from human fetal pancreas. $J$ Lab Clin Med. 2003; 141:342-9. I Article I PubMed

8. Moreno R, Martinez-Gonzalez I, Rosal M, Farwati A, Gratacos E and Aran JM. Characterization of mesenchymal stem cells isolated from the rabbit fetal liver. Stem Cells Dev. 2010; 19:1579-88. | Article I PubMed

9. Koch TG, Heerkens T, Thomsen PD and Betts DH. Isolation of mesenchymal stem cells from equine umbilical cord blood. BMC Biotechnol. 2007; 7:26. | Article | PubMed Abstract | PubMed FullText

10. Shih DT, Lee DC, Chen SC, Tsai RY, Huang CT, Tsai CC, Shen EY and Chiu WT. Isolation and characterization of neurogenic mesenchymal stem cells in human scalp tissue. Stem Cells. 2005; 23:1012-20. | Article | PubMed

11. Rzhaninova AA, Gornostaeva SN and Goldshtein DV. Isolation and phenotypical characterization of mesenchymal stem cells from human fetal thymus. Bull Exp Biol Med. 2005; 139:134-40. I PubMed

12. Bernacki SH, Wall ME and Loboa EG. Isolation of human mesenchymal stem cells from bone and adipose tissue. Methods Cell Biol. 2008; 86:257-78. | Article | PubMed

13. De Coppi P, Pozzobon M, Piccoli M, Gazzola MV, Boldrin L, Slanzi E, Destro $R$, Zanesco L, Zanon GF and Gamba P. Isolation of mesenchymal stem cells from human vermiform appendix. J Surg Res. 2006; 135:85-91. | Article | PubMed

14. Miao Z, Jin J, Chen L, Zhu J, Huang W, Zhao J, Qian H and Zhang X. Isolation of mesenchymal stem cells from human placenta: comparison with human bone marrow mesenchymal stem cells. Cell Biol Int. 2006; 30:681-7. | Article | PubMed

15. Gargett CE, Schwab KE, Zillwood RM, Nguyen HP and WU D. Isolation and culture of epithelial progenitors and mesenchymal stem cells from human endometrium. Biol Reprod. 2009; 80:1136-45. | Article | PubMed Abstract | PubMed FullText

16. Horwitz EM, Prockop DJ, Gordon PL, Koo WW, Fitzpatrick LA, Neel MD, McCarville ME, Orchard PJ, Pyeritz RE and Brenner MK. Clinical responses to bone marrow transplantation in children with severe osteogenesis imperfecta. Blood. 2001; 97:1227-31. | Article | PubMed

17. Horwitz EM, Prockop DJ, Fitzpatrick LA, Koo WW, Gordon PL, Neel M, Sussman M, Orchard P, Marx JC, Pyeritz RE and Brenner MK. Transplantability and therapeutic effects of bone marrow-derived mesenchymal cells in children with osteogenesis imperfecta. Nat Med. 1999; 5:309-13. | Article | PubMed

18. Barzilay R, Melamed E and Offen D. Introducing transcription factors to multipotent mesenchymal stem cells: making transdifferentiation possible. Stem Cells. 2009; 27:2509-15. I Article I PubMed

19. Clark BR and Price EO. Sexual maturation and fecundity of wild and domestic Norway rats (Rattus norvegicus). J Reprod Fertil. 1981; 63:215-20. | Article | PubMed 
Ye et al. Stem Cell Biology and Research 2016,

http://www.hoajonline.com/journals/pdf/2054-717X-3-3.pdf

doi: 10.7243/2054-717X-3-3

20. Grozdanic S, Sakaguchi DS, Kwon YH, Kardon RH and Sonea IM. Characterization of the pupil light reflex, electroretinogram and tonometric parameters in healthy rat eyes. Curr Eye Res. 2002; 25:69-78. | Article | PubMed

21. Grozdanic SD, Betts DM, Sakaguchi DS, Kwon YH, Kardon RH and Sonea IM. Temporary elevation of the intraocular pressure by cauterization of vortex and episcleral veins in rats causes functional deficits in the retina and optic nerve. Exp Eye Res. 2003; 77:27-33. | Article | PubMed

22. Grozdanic SD, Kwon YH, Sakaguchi DS, Kardon RH and Sonea IM. Functional evaluation of retina and optic nerve in the rat model of chronic ocular hypertension. Exp Eye Res. 2004; 79:75-83. | Article | PubMed

23. Uetrecht $\mathrm{J}$. Role of animal models in the study of drug-induced hypersensitivity reactions. AAPS J. 2006; 7:E914-21. | Article | PubMed Abstract | PubMed FullText

24. Yoon YW, Lee DH, Lee BH, Chung K and Chung JM. Different strains and substrains of rats show different levels of neuropathic pain behaviors. Exp Brain Res. 1999; 129:167-71. | PubMed

25. Jacob HJ, Brown DM, Bunker RK, Daly MJ, Dzau VJ, Goodman A, Koike $G$, Kren V, Kurtz T, Lernmark $A$ and et al. A genetic linkage map of the laboratory rat, Rattus norvegicus. Nat Genet. 1995; 9:63-9. | Article | PubMed

26. Levan G, Szpirer J, Szpirer C, Klinga K, Hanson C and Islam MQ. The gene map of the Norway rat (Rattus norvegicus) and comparative mapping with mouse and man. Genomics. 1991; 10:699-718. | PubMed

27. van der Staay FJ and Blokland A. Behavioral differences between outbred Wistar, inbred Fischer 344, brown Norway, and hybrid Fischer 344 x brown Norway rats. Physiol Behav. 1996; 60:97-109. | Article | PubMed

28. Kitada K, Voigt B, Kondo $Y$ and Serikawa T. An integrated rat genome map based on genetic and cytogenetic data. Exp Anim. 2000; 49:119-26. | Article | PubMed

29. Laulederkind SJ, Hayman GT, Wang SJ, Lowry TF, Nigam R, Petri V, Smith JR, Dwinell MR, Jacob HJ and Shimoyama M. Exploring genetic, genomic, and phenotypic data at the rat genome database. Curr Protoc Bioinformatics. 2012; Chapter 1:Unit1 14. | Article | PubMed Abstract | PubMed FullText

30. Dominici M, Le Blanc K, Mueller I, Slaper-Cortenbach I, Marini F, Krause D, Deans R, Keating A, Prockop D and Horwitz E. Minimal criteria for defining multipotent mesenchymal stromal cells. The International Society for Cellular Therapy position statement. Cytotherapy. 2006; 8:315-7. | Article | PubMed

31. Karaoz E, Aksoy A, Ayhan S, Sariboyaci AE, Kaymaz F and Kasap M. Characterization of mesenchymal stem cells from rat bone marrow: ultrastructural properties, differentiation potential and immunophenotypic markers. Histochem Cell Biol. 2009; 132:533-46. | Article I PubMed

32. Oh J, McCloskey MA, Blong CC, Bendickson L, Nilsen-Hamilton M and Sakaguchi DS. Astrocyte-derived interleukin-6 promotes specific neuronal differentiation of neural progenitor cells from adult hippocampus. J Neurosci Res. 2010; 88:2798-809. | Article | PubMed Abstract | PubMed FullText

33. Palmer TD, Takahashi J and Gage FH. The adult rat hippocampus contains primordial neural stem cells. Mol Cell Neurosci. 1997; 8:389-404. | Article | PubMed

34. Gensel JC, Schonberg DL, Alexander JK, McTigue DM and Popovich PG. Semi-automated Sholl analysis for quantifying changes in growth and differentiation of neurons and glia. J Neurosci Methods. 2010; 190:71-9. | Article | PubMed Abstract | PubMed FullText

35. Kutzing MK, Langhammer CG, Luo V, Lakdawala $\mathrm{H}$ and Firestein BL. Automated Sholl analysis of digitized neuronal morphology at multiple scales. J Vis Exp. 2010. | Article | PubMed Abstract | PubMed FullText

36. Schneider CA, Rasband WS and Eliceiri KW. NIH Image to ImageJ: 25 years of image analysis. Nat Methods. 2012; 9:671-5. | PubMed

37. Smits BM, Guryev V, Zeegers D, Wedekind D, Hedrich HJ and Cuppen E. Efficient single nucleotide polymorphism discovery in laboratory rat strains using wild rat-derived SNP candidates. BMC Genomics. 2005; 6:170. | Article | PubMed Abstract | PubMed FullText
38. Hall E, Parton R and Wardlaw AC. Differences in coughing and other responses to intrabronchial infection with Bordetella pertussis among strains of rats. Infect Immun. 1997; 65:4711-7. | Article | PubMed Abstract | PubMed FullText

39. Prockop DJ, Sekiya I and Colter DC. Isolation and characterization of rapidly self-renewing stem cells from cultures of human marrow stromal cells. Cytotherapy. 2001; 3:393-6. | Article | PubMed

40. Sung JH, Yang HM, Park JB, Choi GS, Joh JW, Kwon CH, Chun JM, Lee SK and Kim SJ. Isolation and characterization of mouse mesenchymal stem cells. Transplant Proc. 2008; 40:2649-54. | Article | PubMed

41. Zhang FB, Li L, Fang B, Zhu DL, Yang HT and Gao PJ. Passage-restricted differentiation potential of mesenchymal stem cells into cardiomyocyte-like cells. Biochem Biophys Res Commun. 2005; 336:784-92. | Article I PubMed

42. Kozhevnikova MN, Mikaelian AS, Paiushina OV and Starostin VI. [Comparative characterization of mesenchymal bone marrow stromal cells at early and late stages of culturing]. Izv Akad Nauk Ser Biol. 2008; 156-62. I PubMed

43. Liu Y, Song J, Liu W, Wan Y, Chen X and Hu C. Growth and differentiation of rat bone marrow stromal cells: does 5-azacytidine trigger their cardiomyogenic differentiation? Cardiovasc Res. 2003; 58:460-8. | Article | PubMed

44. Caplan Al and Dennis JE. Mesenchymal stem cells as trophic mediators. $J$ Cell Biochem. 2006; 98:1076-84. | Article | PubMed

45. Crigler L, Robey RC, Asawachaicharn A, Gaupp D and Phinney DG. Human mesenchymal stem cell subpopulations express a variety of neuroregulatory molecules and promote neuronal cell survival and neuritogenesis. Exp Neurol. 2006; 198:54-64. | Article | PubMed

46. Aguayo AJ, Clarke DB, Jelsma TN, Kittlerova P, Friedman HC and Bray GM. Effects of neurotrophins on the survival and regrowth of injured retinal neurons. Ciba Found Symp. 1996; 196:135-44. I PubMed

47. Caffe AR, Soderpalm AK, Holmqvist I and van Veen T. A combination of CNTF and BDNF rescues rd photoreceptors but changes rod differentiation in the presence of RPE in retinal explants. Invest Ophthalmol Vis Sci. 2001; 42:275-82. | Article | PubMed

48. Feng L, Wang CY, Jiang H, Oho C, Dugich-Djordjevic M, Mei L and Lu B. Differential signaling of glial cell line-derived neurothrophic factor and brain-derived neurotrophic factor in cultured ventral mesencephalic neurons. Neuroscience. 1999; 93:265-73. | Article | PubMed

49. Heuckeroth RO, Lampe PA, Johnson EM and Milbrandt J. Neurturin and GDNF promote proliferation and survival of enteric neuron and glial progenitors in vitro. Dev Biol. 1998; 200:116-29. | Article | PubMed

50. Pascual A, Hidalgo-Figueroa M, Piruat JI, Pintado CO, Gomez-Diaz R and Lopez-Barneo J. Absolute requirement of GDNF for adult catecholaminergic neuron survival. Nat Neurosci. 2008; 11:755-61. | Article | PubMed

51. Schuettauf F, Vorwerk C, Naskar R, Orlin A, Quinto K, Zurakowski D, Dejneka NS, Klein RL, Meyer EM and Bennett J. Adeno-associated viruses containing bFGF or BDNF are neuroprotective against excitotoxicity. Curr Eye Res. 2004; 29:379-86. | Article | PubMed

52. Zurn AD, Winkel L, Menoud A, Djabali K and Aebischer P. Combined effects of GDNF, BDNF, and CNTF on motoneuron differentiation in vitro. $J$ Neurosci Res. 1996; 44:133-41. | PubMed

53. Harper MM, Adamson L, Blits B, Bunge MB, Grozdanic SD and Sakaguchi $D S$. Brain-derived neurotrophic factor released from engineered mesenchymal stem cells attenuates glutamate- and hydrogen peroxide-mediated death of staurosporine-differentiated RGC-5 cells. Exp Eye Res. 2009; 89:538-48. | Article | PubMed Abstract | PubMed FullText

54. Pan HC, Cheng FC, Chen CJ, Lai SZ, Lee CW, Yang DY, Chang MH and Ho SP. Post-injury regeneration in rat sciatic nerve facilitated by neurotrophic factors secreted by amniotic fluid mesenchymal stem cells. J Clin Neurosci. 2007; 14:1089-98. | Article | PubMed

55. Oh J, Recknor JB, Recknor JC, Mallapragada SK and Sakaguchi DS. Soluble factors from neocortical astrocytes enhance neuronal differentiation of neural progenitor cells from adult rat hippocampus on micropatterned polymer substrates. J Biomed Mater Res A. 2009; 91:575-85. | Article | PubMed Abstract | PubMed FullText 
Ye et al. Stem Cell Biology and Research 2016,

56. Stewart AL, Anderson RB, Kobayashi K and Young HM. Effects of NGF, NT-3 and GDNF family members on neurite outgrowth and migration from pelvic ganglia from embryonic and newborn mice. BMC Dev Biol. 2008; 8:73. | Article | PubMed Abstract | PubMed FullText

57. Labelle $C$ and Leclerc N. Exogenous BDNF, NT-3 and NT-4 differentially regulate neurite outgrowth in cultured hippocampal neurons. Brain Res Dev Brain Res. 2000; 123:1-11. | Article | PubMed

58. Lander AD. Molecules that make axons grow. Mol Neurobiol. 1987; 1:213-245. | Article

59. Hynes RO and Lander AD. Contact and adhesive specificities in the associations, migrations, and targeting of cells and axons. Cell. 1992; 68:303-22. | Article | PubMed

60. Carri NG, Perris R, Johansson $S$ and Ebendal T. Differential outgrowth of retinal neurites on purified extracellular matrix molecules. J Neurosci Res. 1988; 19:428-39. | Article | PubMed

61. Bixby JL and Harris WA. Molecular mechanisms of axon growth and guidance. Annu Rev Cell Biol. 1991; 7:117-59. | Article | PubMed

62. Tomaselli KJ. Beta 1-integrin-mediated neuronal responses to extracellular matrix proteins. Ann N Y Acad Sci. 1991; 633:100-4. | Article | PubMed

63. Harper MM, Ye EA, Blong CC, Jacobson ML and Sakaguchi DS. Integrins contribute to initial morphological development and process outgrowth in rat adult hippocampal progenitor cells. J Mol Neurosci. 2010; 40:26983. | Article | PubMed

64. Geiger B, Bershadsky A, Pankov R and Yamada KM. Transmembrane crosstalk between the extracellular matrix--cytoskeleton crosstalk. Nat Rev Mol Cell Biol. 2001; 2:793-805. | Article | PubMed

65. Schinkothe $T$, Bloch $W$ and Schmidt $A$. In vitro secreting profile of human mesenchymal stem cells. Stem Cells Dev. 2008; 17:199-206. | Article | PubMed

66. Johnson EC, Guo Y, Cepurna WO and Morrison JC. Neurotrophin roles in retinal ganglion cell survival: lessons from rat glaucoma models. Exp Eye Res. 2009; 88:808-15. | Article | PubMed Abstract | PubMed FullText

67. Harper MM, Grozdanic SD, Blits B, Kuehn MH, Zamzow D, Buss JE, Kardon $\mathrm{RH}$ and Sakaguchi DS. Transplantation of BDNF-secreting mesenchymal stem cells provides neuroprotection in chronically hypertensive rat eyes. Invest Ophthalmol Vis Sci. 2011; 52:4506-15. | Article | PubMed Abstract | PubMed FullText

\section{Citation:}

Ye E-A, Chawla SS, Khan MZ and Sakaguchi DS. Bone marrow-derived mesenchymal stem cells (MSCs) stimulate neurite outgrowth from differentiating adult hippocampal progenitor cells. Stem Cell Biol Res. 2016; 3:3. http://dx.doi.org/10.7243/2054-717X-3-3 